\title{
Racismo e a derrota que não foi esquecida: uma análise dos discursos de Mário Filho e da imprensa escrita acerca da final da Copa do Mundo de 1950
}

\author{
Natasha Santos * \\ André Mendes Capraro ** \\ Riqueldi Straub Lise ***
}

\begin{abstract}
Resumo: O objetivo deste trabalho é comparar o discurso estabelecido por Mário Filho na segunda edição de "O Negro no Futebol Brasileiro", de 1964, e as notícias dos jornais da época, no que se refere à culpa atribuída aos jogadores negros pela derrota de 1950. Eles foram realmente culpados pela imprensa brasileira ou se está falando de uma "tradição inventada" por Mário Filho no entorno futebolístico? A fim de solucionar a questão, utilizou-se dos preceitos da análise do discurso e foram selecionados dois periódicos de grande circulação nacional: o jornal "O Estado de São Paulo" e a revista "O Cruzeiro". Com base nas matérias averiguadas, pôde-se perceber que não houve qualquer tipo de preconceito racial. Assim, pode-se dizer que o discurso de Mário Filho, ao abordar o "recrudescimento do racismo", a partir da narrativa da derrota de 1950, configura-se como uma tradição inventada. Palavras-chave: Futebol: história. Preconceito. Imprensa.
\end{abstract}

\footnotetext{
*Graduado em Educação Física. Mestranda em História pela Universidade Federal do Paraná. Pesquisadora do Núcleo de Pesquisa Futebol \& Sociedade - UFPR. Curitiba. PR, Brasil. E-mail: nata.shas@ig.com.br

**Graduado em Educação Física. Graduado em Psicologia. Mestre em História. Doutor em História. Professor adjunto da Universidade Federal do Paraná. Pesquisador do Núcleo de Estudos Futebol e Sociedade - UFPR. Coordenador do Centro de Memória do Departamento de Educação Física, UFPR. Curitiba, PR, Brasil. E-mail: andrecapraro@onda.com.br

*** Graduado em Educação Física. Pesquisador júnior do Núcleo de Pesquisa Futebol \& Sociedade - UFPR. Curitiba, PR, Brasil. E-mail: ricklise@ig.com.br
} 


\section{INTRODUÇÃO}

16 de julho de 1950. Realizava-se a final da Copa do Mundo do Brasil, na qual se enfrentariam as seleções uruguaia e brasileira. Era grande a expectativa em torno desta última, que vinha fazendo bons jogos e precisava apenas de um empate (PERDIGÃO, 2000; NOGUEIRA, SOARES, MUYLAERT, 1994). A esta data, "O Estado de São Paulo" noticiava: "Grande expectativa em todo o Brasil pelo desfecho do importante jogo, que deverá inscrever o nome do nosso País entre os vencedores do Campeonato Mundial de Futebol" (O ESTADO DE SÃO PAULO, 16 jul. 1950, p.14).

Entretanto, mesmo diante da vantagem do empate, o selecionado nacional perdeu o jogo para o Uruguai, estabelecendo o que foi uma das maiores e inesquecíveis decepções que o brasileiro enfrentou. Diante disso, na reformulação da obra "O Negro no Futebol Brasileiro", em 1964, Mário Filho reconhece o racismo no futebol, bem como na sociedade brasileira (SOARES, 1999). E, para tal, o literato se utiliza exatamente da final da Copa de 50 e dos três atletas negros do selecionado brasileiro (em especial o goleiro Barbosa) que teriam sido responsabilizados pela derrota (RODRIGUES FILHO, 1964).

O uso recorrente de Mário Filho na discussão do racismo e mesmo da identidade nacional, como afirma Soares (1999), acaba por confirmar e fazer verdadeira a narrativa amplamente difundida, devido à utilização da obra como prova para determinadas interpretações, sem ser devidamente questionada. Ora, referindose ao gênero literário, Ginzburg (2004) estabelece o que seria a literatura de fronteira, correspondente a narrativas com determinado grau de pretensão à verdade e que, por isso, se situam na linha tênue entre ficção e realidade. Um desses gêneros é o ensaio de cunho sociológico (CAPRARO, 2007), no qual se pode estabelecer "O Negro no Futebol Brasileiro"1, que acaba por evidenciar um debate

${ }^{1}$ A classificação do gênero de "O Negro no Futebol Brasileiro" é bastante discutida entre pesquisadores das ciências sociais, podendo ser encontradas classificações como ensaio sociológico puro, como romance, como pesquisa histórica e mesmo como um texto memorialístico (CAPRARO, 2007). "

Movimento, Porto Alegre, v. 16, n. 04, p. 191-208, outubro/dezembro de 2010. 
de relevância sócio-cultural, segundo uma estética que o aproxima da literatura; somado ao forte envolvimento do autor com o objeto de estudo, o que apontaria para uma relativização das ideias postas. Por outro lado, de acordo com o parecer de Gilberto Freyre, exposto no prefácio da obra, Mário Filho se utiliza de um criterioso levantamento de fontes históricas. Entretanto, Freyre mantinha uma relação de proximidade com Mário Filho e se torna difícil saber como (e se) as fontes foram realmente levadas em consideração, haja vista que o estilo de escrita adotado pelo cronista ignora citações, o que permite relativizar tal informação.

Assim, o objetivo deste trabalho é cruzar as ideias propostas na edição reformulada de 1964 com as notícias veiculadas por alguns periódicos da época, no que se refere à culpa atribuída aos jogadores negros pela derrota de 1950 . Eles foram culpados pela imprensa brasileira ou se está falando de uma "tradição inventada"2 no entorno futebolístico?

A fim de compreender uma das facetas do discurso estabelecido após a derrota da Copa de 1950, as fontes a serem utilizadas nesta pesquisa, que se caracteriza como histórica, são a segunda edição de "O Negro no Futebol Brasileiro" (1964) e dois periódicos de grande circulação na década em questão: a revista "O Cruzeiro" (de veiculação semanal, foram analisadas as notícias da semana de 29 de julho de 1950) e o jornal "O Estado de São Paulo" (no dia da final da Copa de 1950, 16 de julho de 1950, e no dia posterior, 18 de julho de 1950). A escolha de tais veículos se efetivou por dois aspectos: 1) ambos possibilitam uma visão ampliada do tema, por serem populares, embora o primeiro fosse símbolo de sofisticação no mercado editorial, enquanto o segundo figurava nos setores mais tradicionais e conservadores do país; e 2) porque um era estabelecido no estado do Rio de Janeiro, ou seja, mais envolvido com a Copa do Mundo do

2Por 'tradição inventada' entende-se um conjunto de práticas, normalmente reguladas por regras tácitas ou abertamente aceitas; tais práticas, de natureza ritual ou simbólica, visam inculcar certos valores e normas de comportamento através da repetição, o que implica automaticamente uma continuidade em reação ao passado. Aliás, sempre que possível, tentase estabelecer continuidade com um passado histórico apropriado" (HOBSBAWM, RENGER, 1997, p.9).

Movimento, Porto Alegre, v. 16, n. 04, p. 191-208, outubro/dezembro de 2010. 
que o jornal paulista, que estaria mais distante em relação à expectativa da organização do jogo festivo.

Para analisar as fontes em questão, optou-se pela utilização dos preceitos de Ginzburg (1990), quanto ao "paradigma indiciário", no cruzamento das fontes, somados à análise do discurso e literária. Buscou-se considerar essencialmente a ideia de que todo discurso é carregado de determinada ideologia, compatível com o lugar de onde vem a fala (FOUCAULT, 1998). Portanto, faz-se necessário levar em conta o contexto em que determinada fala se constitui e a sua intertextualidade, ou seja, o fato de alguns discursos influenciarem outros. Somado a isso, e sabendo que "O Negro no Futebol Brasileiro" é aqui considerado um gênero fronteiriço da literatura, cabe utilizar a tese de Antonio Candido (2000), de que o texto se funde ao contexto em que a obra foi escrita. Isto é, os fatores externos (história social) se tornam internos ao texto, fundindo-se ao estilo literário do autor.

\section{Mário Filho e o meio intelectual}

Mário Filho, filho do jornalista Mário Rodrigues, manteve desde cedo uma relação próxima ao cotidiano dos jornais, estabelecida mais fortemente com as páginas esportivas. Mário Filho contribuiu significativamente para a popularização do futebol. Em 1936, comprou o "Jornal dos Sports", que seria um dos mais conceituados periódicos do país (CASTRO, 1992). O cronista fez parte do rol de literatos que procurou definir e disseminar o que seria um ideal de brasilidade (SILVA, 2006).

Já no século XIX, intelectuais como Sílvio Romero, Euclides da Cunha e Nina Rodrigues, buscaram pensar a emergente realidade brasileira sob a hegemônica visão europeia, estabelecendo o Brasil em um estágio civilizatório inferior (ORTIZ, 1994). A compreensão desse atraso culminou com a ênfase no estudo do "caráter nacional", identificado na mestiçagem. Porém, mesmo se tornando corrente o mito das três raças, as teorias apontavam para uma superioridade branca, mantendo o negro e o índio como entraves para o processo de civilização do país. É durante a década de 1930 que intelectuais

Movimento, Porto Alegre, v. 16, n. 04, p. 191-208, outubro/dezembro de 2010. 
como Freyre, Prado Jr. e Buarque de Holanda, debatem sobre a identidade brasileira e elaboram teses a respeito de uma brasilidade. Freyre influenciou literatos, que estabeleceram uma nova interpretação do Brasil, na qual a figura do mestiço se fazia valer nas representações futebolísticas (SOARES, 2003).

Ao título de "O Negro no Futebol Brasileiro", Mário Filho buscou mostrar a participação do futebol na constituição de uma nação integral, a partir das relações raciais no esporte que teriam superado as tensões uma vez existentes (HELAL; GORDON JR., 2001).

Poder-se-ia dizer que seria '"O Negro no Futebol Brasileiro' (1947) - uma espécie de 'Casa Grande \& Senzala' urbana, um livro equivalente na historiografia racial ao de Gilberto Freyre" (CASTRO, 1992, p.222). Como afirma o próprio Freyre:

Êste aspecto do desenvolvimento do futebol no Brasil, fixa-o Mário Filho [...] um luxo de pormenores significativo, que tornam seu ensaio uma obra de importância para o estudo sociológico e psicológico da ascensão do negro e do mulato na sociedade brasileira (FREYRE In RODRIGUES FILHO, 1964, Prefácio).

A miscigenação brasileira, que antes causava vergonha, no futebol se caracterizou como o motivo dos bons resultados (SOARES; LOVISOLO, 2003). Mário Filho, ao tratar do negro no futebol, foi influenciado não apenas por Freyre, mas também por um "freyrismo popular", sendo este uma crença de que no Brasil não existiria preconceito racial (SOARES, 2001).

Na segunda edição da obra (1964), entretanto, Mário Filho aborda um recrudescimento do racismo no Brasil, construído e exemplificado especialmente pelas justificativas à derrota da Copa de 1950. Segue-se a análise.

Movimento, Porto Alegre, v. 16, n. 04, p. 191-208, outubro/dezembro de 2010. 


\section{3 "A VEZ DO PRÊTO"}

Publicada em 1947, a obra de Mário Filho teve a sua segunda edição ampliada em 1964. Nesta, o autor busca reformular algumas discussões, bem como denunciar o que representaria um "recrudescimento" do racismo, o qual seria um agravo do preconceito antes conhecido. Para tal, no capítulo intitulado "A vez do Prêto", o literato se utiliza da derrota da seleção brasileira na Copa do Mundo de 1950, quando alguns jogadores negros foram responsabilizados pelo fracasso esportivo, que recaía nos demais setores da sociedade.

A análise do discurso busca a apreensão da singularidade, o que distingue um discurso do outro, ao mesmo tempo em que visa à construção de uma generalidade, inserindo-o em um domínio comum (ORLANDI, 1983). Assim, faz-se necessário considerar o contexto em que determinada fala se constitui e a sua intertextualidade - o fato de alguns discursos influenciarem outros. Pois bem, tal como exposto, quanto ao modo de pensar o Brasil, Mário Filho foi bastante influenciado pela tese de Gilberto Freyre, o qual, inclusive, escreveu o prefácio da obra supracitada. Desse modo, há de se levar em consideração o esforço de Mário Filho em estabelecer um ideário de brasilidade em torno da miscigenação, expressa sobretudo por meio do futebol.

Esse esforço se confirma em trechos como: "Mas, ao mesmo tempo que se observava êsse recrudescimento de racismo, o brasileiro escolhia um ídolo às avessas: Obdúlio Varela, mulato uruguaio, de cabelo ruim" (RODRIGUES FILHO, 1964, p.336). Ou ainda: "E o brasileiro se esquecia, ou talvez não se esquecesse, pelo contrário, que Obdúlio Varela era mulato" (Ibidem). Ora, tomando por base as ideias de Fiorin (1988) e Foucault (1998), todo discurso é, inevitavelmente, carregado de ideologia, haja vista que mesmo a neutralidade se caracterizaria como uma posição política. Pois bem, entenda-se aqui ideologia como ideias que justificam ou explicam determinada ordem social, sob uma visão de mundo específica - a do autor. Essa ideologia pode se apresentar de maneira direta ou sob o aspecto de "falsa consciência", que oculta a essência da ordem

Movimento, Porto Alegre, v. 16, n. 04, p. 191-208, outubro/dezembro de 2010. 
social em questão, isto é, uma inversão da realidade estabelecida pelo sujeito da fala, com o intuito de amenizar sua colocação diante da situação a que se refere (FIORIN, 1988).

A postura de Mário Filho no trecho em questão parece referir a essa "falsa consciência". O cronista questiona a incoerência de culpar os atletas negros pela derrota e em seguida escolher um ídolo mulato (uruguaio). Entretanto, não deixa clara a opinião de que o povo estava consciente disso, ao contrário: estabelece o nãoesquecimento como possibilidade sutil ao leitor, a qual acaba por ser enfatizada no esquecimento, como que de maneira irônica. Ou seja, ao afirmar que "o brasileiro se esquecia", Mário Filho busca explicitar a contradição do povo, que não havia esquecido que Obdulio era mulato. Assim, conta-se com a hipótese de que o autor busca justificar o recrudescimento do racismo pela derrota na Copa de 1950, tendo em vista que, caso o Brasil fosse campeão, Barbosa, Juvenal e Bigode é que seriam os ídolos dos brasileiros. Nesse sentido, Mário Filho aponta que, para os brasileiros, antes de Obdulio Varela ser mulato, a figura do herói ideal retratado na seleção uruguaia era a figura de um vencedor.

Na construção desse ideário de brasilidade em torno da miscigenação racial e do futebol, atrelado ao reconhecimento do preconceito, é possível perceber que Mário Filho apresenta certa contradição no discurso: se é um caso típico de racismo, por que os outros atletas negros e mestiços, mencionados pelo autor, também não foram responsabilizados? Ora, Ginzburg (1990), ao tratar do "paradigma indiciário", reforça a busca por indícios menos influenciáveis pelo estilo de escrita de autor, os quais, portanto, revelariam o lugar de onde esse sujeito fala. Isto é, trata da busca por sinais que permitam clarear facetas de uma realidade opaca presente no discurso.

Nesse sentido, pode-se inferir que o literato tratava do racismo como o resultado de uma necessidade do brasileiro em achar um culpado para a tragédia que, segundo a descrição do início do trecho em foco, abalou as estruturas do país inteiro, representando o seu próprio fracasso. Segundo o autor, não se tratava de preconceito de

Movimento, Porto Alegre, v. 16, n. 04, p. 191-208, outubro/dezembro de 2010. 
cor propriamente dito - já que o ídolo que o povo vislumbrava era mulato e alguns jogadores negros foram poupados de críticas -, mas de uma decepção tão forte que abalou a identidade refletida por meio do mestiço, no futebol. Ou seja, mesmo com a intenção de reconhecer o racismo no Brasil, por meio de seu ensaio, Mário Filho não assume completamente a existência de tal preconceito. Pelo contrário, insiste em tratar o racismo como consequência de uma frustração, e não uma aversão constante ao mestiço.

Com uma sequência de largas vitórias e apenas um empate ${ }^{3}$, o Brasil era o favorito à conquista da Copa de 1950, precisando apenas de um empate contra a seleção uruguaia, cujos resultados deixavam a desejar, se comparados aos brasileiros ${ }^{4}$. Toda a expectativa do país, que ouvia os jogos pelo rádio nas casas, repartições ou comércios (ARAÚJO, 2001), refletia, além da possibilidade de apresentar o melhor futebol do mundo, a capacidade de organização; ou seja, a oportunidade de o Brasil se mostrar para o mundo. Assim, é como se o recrudescimento do racismo fosse o resultado de uma grande decepção diante da derrota: "Na verdade sentíamo-nos todos culpados. A culpa era nossa. [...] O brasileiro que acusava os brasileiros naturalmente desabafava para ficar de fora. Ou ver se ficava de fora" (RODRIGUES FILHO, 1964, p.335).

Considerando que a obra se caracteriza como literatura de fronteira - um ensaio de cunho sociológico -, deve-se levar em conta que esta se encontra no limiar tênue entre ficção e verdade, o envolvimento e estilo estético do autor se fundem ao seu contexto histórico-social. Nesse sentido, como defende Antonio Candido (2000), o elemento social não deve ser considerado externamente à produção, porém, como um fenômeno externo (contexto) que se torna interno à obra. Assim, a fusão entre texto e contexto assimila a dimensão histórica-social como "fator de arte".

${ }^{3}$ Os resultados do selecionado brasileiro, até a final contra o Uruguai foram: Brasil 4 X 0 México, Brasil 2 X 2 Suíça, Brasil 2 X 0 lugoslávia, Brasil 7 X 1 Suécia, Brasil 6 X 1 Espanha (ABRAHÃO, SOARES, 2009, p.17).

${ }^{4} \mathrm{O}$ Uruguai venceu a Suécia por $3 \times 2$ (o gol de desempate foi feito nos minutos finais) empatou em $2 \times 2$ com a Espanha.

Movimento, Porto Alegre, v. 16, n. 04, p. 191-208, outubro/dezembro de 2010. 
Não obstante, há de se notar que Mário, assim como seu irmão Nelson Rodrigues, tende a recorrer ao "exagero" para consolidar seu discurso. Inicia com os "gritos de viúvas sicilianas" (RODRIGUES FILHO, 1964, p.335) e vai até o sentimento de culpa generalizado, como que denunciando o que seria um fracasso coletivo e multifacetado. Tudo para enfatizar que a derrota atingira a todos, ultrapassando as linhas do campo: uma derrota da nação.

Inevitavelmente, o futebol foi incorporado à identidade nacional, por meio de uma tradição inventada (HOBSBAWM, RENGER, 1997) e reafirmada pelos literatos, que acentuavam que as peculiaridades brasileiras seriam a ginga, a malícia e o improviso no jogo. É nesse sentido que se estabelece a necessidade em encontrar um culpado, uma vez que o Brasil não pode perder para um adversário técnica ou taticamente superior, mas, pelo contrário, perderia apenas diante de um erro (jamais técnico) do próprio brasileiro. Afinal, ninguém poderia ser superior ao então país do futebol.

Desse modo, o racismo denunciado por Mário Filho, na segunda edição de sua obra, fica claro ao surgirem os culpados pela derrota: "Assim três prêtos foram escolhidos como bodes expiatórios: Barbosa, Juvenal e Bigode. Os outros mulatos e prêtos ficaram de fora: Zizinho, Bauer e Jair da Rosa Pinto" (RODRIGUES FILHO, 1964, p.336). Aqui, o autor evidencia a intensificação do racismo: "Mas quase todos se viravam era contra os prêtos do escréte. [...] - A verdade é que somos uma sub-raça. Uma raça de mestiços. Uma raça inferior" (Ibidem, p.335).

A difusão de tal ideia pode ser explicada segundo a lógica de que Ginzburg (2006) se utiliza: a circularidade, haja vista as influências culturais recíprocas entre diferentes classes. Vale lembrar que o trecho analisado faz parte da edição de 1964, isto é, quando Mário Filho reformulou seu livro e acrescentou tal discurso, o Brasil já era bicampeão mundial. Assim, ficou relativamente fácil, em se tratando de alguém que escrevia bem, formular (ou ao menos acentuar) uma dificuldade inicial, seguindo a construção de um enredo hollywoodiano clássico - o mocinho tem uma grande dificuldade no início que será, após muita luta, superada ao final.

Movimento, Porto Alegre, v. 16, n. 04, p. 191-208, outubro/dezembro de 2010. 


\section{A vez dA NOTÍCIA}

Criada em 1928 e reformulada em 1945, "O Cruzeiro" foi a primeira revista de circulação nacional a introduzir a linguagem da fotorreportagem (ANDRADE, CARDOSO, 2001). Parte do império dos Diários Associados de Chateaubriand, foi a principal revista do Brasil na época, dominando esse mercado por décadas, já que possuía uma excelente distribuição. Tratava-se de um semanário de entretenimento, com muitas fotografias e títulos, cuja linha editorial era direcionada a um público variado, a fim de ser uma revista popular (BARBOSA, 2002).

"O Estado de São Paulo", por sua vez, é um jornal paulista de tradição e de resistência. Fundado em 1875, pertencia a um grupo de republicanos - de posição contrária ao regime monárquico e à escravidão. Sem perder o caráter de denunciar toda e qualquer arbitrariedade política, o periódico foi, por algumas vezes censurado pelos governos vigentes - como na Revolução de 1924, durante o Estado Novo e o regime militar (CARDOSO, 2010).

Em se tratando do pós 16 de julho de 1950, "O Estado de São Paulo" estampou na página esportiva uma descrição dos fatos, sem poesia, nem metáfora: "Atuando com grande entusiasmo e espírito de luta, a representação uruguaia venceu o IV campeonato mundial de futebol" (O ESTADO DE SÃO PAULO, 18.07.1950, p.8). Ao longo das duas páginas, conta-se com uma narrativa descritiva do que foi a final da Copa, com fortes críticas ao treinador Flávio Costa.

\footnotetext{
Desde os passos iniciais para a formação do quadro nacional, ficaram bem nítidas a insegurança e a incapacidade do técnico nomeado pela C. B. D., o sr. Flavio Costa infeliz na convocação dos futebolistas, infeliz no seu aproveitamento e infeliz ainda na sua orientação (O ESTADO DE SÃO PAULO, 18.07.1950, p.8).
}

Aqui, pode-se perceber um discurso mais técnico, preso efetivamente ao desempenho brasileiro desde o início da competição, e menos emotivo do que o de Mário Filho.

Movimento, Porto Alegre, v. 16, n. 04, p. 191-208, outubro/dezembro de 2010. 
Foucault (1998), ao se referir ao discurso e suas relações de poder, apresenta a vontade de verdade como princípio de exclusão de determinada fala. Assim, para que o discurso seja considerado "verdade", bem como para que seja ouvido, ele deve estar inserido no chamado "verdadeiro", respeitando certas regras (tácitas) discursivas presentes no contexto ao qual se faz parte.

Em tese, o princípio do jornal, ou de qualquer veículo de comunicação, é a busca pela verdade, sob uma posição neutra. Entretanto, sabe-se que esta neutralidade é passível de questionamentos, sobretudo se levar em consideração as relações de poder no entorno discursivo. Nesse sentido, o periódico assume um caráter objetivo, oposto à narrativa fronteiriça desenrolada por Mário Filho.

Ao tratar da mágoa do brasileiro diante da derrota, o literato personifica a fala do torcedor e trata de uma raça de mestiços que "Na hora de aguentar o pior a gente se borrava todo. Como Barbosa quando estreara no escréte brasileiro" (RODRIGUES FILHO, 1964, p.335). Ora, pautando-se mais uma vez nos indícios e sinais transcritos pelo cronista, chega-se à descrição exata do que Nelson Rodrigues chamou de complexo de vira-latas em 1958. Ou seja, enquanto o periódico trata da partida em si, Mário Filho extrapola os limites técnicos e aborda o que seria o principal motivo do fracasso: o sentimento de inferioridade diante de estrangeiros.

A notícia prossegue descrevendo os jogadores: "Barbosa esteve irreconhecível. Augusto ótimo e Juvenal muito bom. [...] Bigode não merece sequer menção. [...] Ademir, bom nas entradas, falhou completamente nos chutes" (O ESTADO DE SÃO PAULO, 18.07.1950, p.9).

A partir deste excerto, chega-se a um novo impasse, em relação ao discurso de Mário Filho: o periódico afirma que Juvenal estava "muito bom". Mas se Juvenal estava jogando relativamente bem, não caberia, portanto, o trecho em que o literato diz que "três prêtos foram escolhidos como bodes expiatórios: Barbosa, Juvenal e Bigode" (RODRIGUES FILHO, 1964, p.335). O jornal reconhece a má atuação de Bigode e Barbosa, inclusive atribuindo a estes o foco da

Movimento, Porto Alegre, v. 16, n. 04, p. 191-208, outubro/dezembro de 2010. 
derrota: "É verdade que para o triste resultado da peleja contribuíram eficazmente dois fatores, ambos da seleção auri-verde: Bigode e Barbosa" (O ESTADO DE SÃO PAULO, 18.07.1950, p.8). Recorrendo ao paradigma indiciário (GINZBURG, 1990), conta-se com indícios de que a atuação de Juvenal não foi unanimemente digna de colocar o atleta na posição de "bode expiatório".

Entretanto, a notícia em si não dá margens a qualquer tipo de interpretação racista. Bigode e Barbosa assumiram um papel relevante na derrota brasileira pelo fato de terem se apresentado pessimamente. A matéria não entra no mérito racial, mas conclui que o Brasil perdeu porque jogou mal; e jogou mal por "obra do destino":

\begin{abstract}
Quem poderia imaginar que Bigode, regular nas suas excelentes produções, viesse a atuar daquela maneira? E quem poderia imaginar Barbosa capaz de atuar no arco como o faria um principiante? E mais: quem poderia admitir que Ademir errasse todos os chutes que enviou ao arco de Maspoli? Ficamos desprotegidos pela sorte (O ESTADO DE SÃO PAULO, 1950, p.9).
\end{abstract}

Note-se que o jornal cita a má atuação de Ademir, atleta branco não listado por Mário Filho, o que abre uma lacuna ainda maior no discurso do literato freyreano. Se realmente houvesse qualquer tipo de intenção racista na análise produzida pelo jornal, este não citaria os erros de Ademir. Mais uma vez, cabe considerar a inserção do discurso em um domínio comum (ORLANDI, 1983). Assim, mesmo que o periódico não faça qualquer menção ao comportamento racista de que trata Mário Filho, pode-se perceber a intertextualidade entre os discursos, já que ambos não reconhecem que a derrota como uma falha técnica ou tática, mas como destino. Seja este retratado como "sorte" ou inferioridade racial.

"O Cruzeiro", a partir de um discurso menos técnico, explora o futebol como representação da identidade nacional, defendendo os jogadores - negros ou não - e atribuindo aos brasileiros, inclusive à imprensa, a culpa pela derrota.

Movimento, Porto Alegre, v. 16, n. 04, p. 191-208, outubro/dezembro de 2010. 
Primariamente, se utiliza da metáfora da traição conjugal de uma diva do cinema, a fim de defender Barbosa: "Sim, a meta de Barbosa quase virginal, quase imaculada, tão pura e sem pecado como Ingrid Bergman antes de Rossellini" (O CRUZEIRO, 29.07.1950, p.15). Cabe lembrar, aqui, o fato de que "O Cruzeiro" visava a um público amplo, incluindo mulheres que, via de regra, eram mais entendidas em cinema do que em futebol. Dessa maneira, a revista busca disseminar um ideal de enaltecimento da seleção, transferindo a responsabilidade da derrota para o povo brasileiro: "Todos nós somos culpados. Que história é essa, agora, de descarregar sobre os ômbros de Bigode, de Barbosa, de Jair, de Flávio Costa, a responsabilidade por uma derrota que é tão nossa quanto deles? [...]" (Ibidem, p.14).

Ainda nesta matéria, o título "Derrota da Máscara" evidencia a culpa de todos os brasileiros, desde jornalistas a torcedores: tendo em vista a certeza prévia de que o selecionado nacional seria campeão. A vantagem do empate teria mascarado o jogo difícil e ludibriado torcedores e jogadores: "Criamos a lenda de sua invencibilidade e fizemos com que êles se esquecessem do ilógico no futebol" (O CRUZEIRO, 29.07.1950, p.19).

Essa euforia e expectativa de que trata o semanário pôde ser conferida nas páginas de "O Estado de São Paulo", no dia da partida:

\footnotetext{
Não há brasileiro, por mais avesso que seja ao futebol, que não tenha a sua atenção voltada para a peleja entre os quadros do Brasil e do Uruguai. [...] Bastará ao Brasil o empate, pois tem um ponto de vantagem na tabela. Ninguém fala nisso, todavia $(\mathrm{O}$ ESTADO DE SÃO PAULO, 16.07.1950, p. 14).
}

A expectativa não estava apenas quanto ao título, mas principalmente no que se referia à vitória sobre o selecionado uruguaio. Devido à convincente campanha que a equipe brasileira fez ao longo do campeonato, para o povo não era suficiente conquistar a taça com a vantagem do empate. Era preciso vencer, como foi contra outras seleções. Desse modo, percebe-se uma compatibilidade entre o discurso identitário de "O Cruzeiro" e o de Mário Filho, ao

Movimento, Porto Alegre, v. 16, n. 04, p. 191-208, outubro/dezembro de 2010. 
dizer que "Na verdade sentíamo-nos todos culpados. A culpa era nossa. Não tínhamos aguentado uma vitória, a das Touradas de Madri, contra a Espanha" (RODRIGUES FILHO, 1964, p.335).

Nesse sentido, pode-se recorrer ao campo hipotético: tendo em vista o estilo do texto publicado pela revista carioca e sabendo que Nelson Rodrigues, adepto das formulações de Mário Filho, trabalhou em "O Cruzeiro", escrevendo os romances de Susana Flag (CASTRO, 1992), é possível que Nelson tenha algum tipo de envolvimento com a formulação exposta.

\section{CONSIDERAÇõES FINAS}

Sem entrar no mérito se existe ou não racismo no Brasil, não foi encontrado, nas notícias da época, nenhum indício que reiterasse o argumento racista em que se pautou Mário Filho. Com base nas matérias averiguadas, pôde-se perceber que, em determinados discursos, Bigode e Barbosa aparecem, sim, como os principais culpados pelo desempenho brasileiro aquém do esperado. Entretanto, não se estabelece, qualquer tipo de preconceito racial, mesmo porque, os demais negros da equipe atuaram de maneira satisfatória, segundo os periódicos.

As contradições que Mário Filho estabeleceu em sua própria fala, ao afirmar, por exemplo, que alguns negros da equipe ficaram alheios à culpa pela derrota, o que não aconteceria se o discurso contra Bigode e Barbosa realmente fossem de cunho racista. Tais contradições, entretanto, eram necessárias para corroborar a tese de que a brasilidade estava na miscigenação racial, presente na primeira edição de "O Negro no Futebol Brasileiro", agregando o reconhecimento da existência do racismo. Nesse sentido, Mário Filho se utiliza do sentimento de inferioridade que o brasileiro apresentava diante do estrangeiro. Sentimento este que, quando superado (como nas Copas de 1958 e 62), promove a aclamação da superioridade mestiça, expressa essencialmente pelo futebol.

Ora, Soares (2002), ao investigar crônicas esportivas de Mário Filho, bem como as notícias do "Jornal dos Sports" posteriores à

Movimento, Porto Alegre, v. 16, n. 04, p. 191-208, outubro/dezembro de 2010. 
final do campeonato mundial de 1950, não encontrou discursos que evidenciassem uma intensificação racista, conforme alega a segunda edição da obra.

Assim, pode-se afirmar que o discurso de Mário Filho, acerca do "recrudescimento do racismo", configura-se como uma tradição inventada, definida por Hobsbawm e Renger (1997), que acaba por implicar uma determinada continuidade em relação a algum fato passado, compartilhando de fatores inerentes à noção de circularidade (GINZBURG, 2006).

Essa tradição inventada, desenvolvida por Mário Filho, foi amplamente aceita e difundida devido à representação do literato, um cronista respaldado pelo meio literário e pelo próprio Gilberto Freyre, em cuja tese se apoiou. Além disso, essas ideias se popularizaram pelo acesso a um grande contingente populacional que apreciava o futebol, por meio dos jornais.

Movimento, Porto Alegre, v. 16, n. 04, p. 191-208, outubro/dezembro de 2010. 
Racism and the defeat that was not forgotten: an analysis of the discourses of Mario Filho and the press about the final of the World Cup of 1950

Abstract: The objective of this research is to compare the discourse established by Mário Filho in the second edition of "O Negro no Futebol Brasileiro", from 1964, and the news reported by newspapers of the time, related to the blame attributed to black players for the defeat of 1950 . Were they really considered guilty by Brazilian press or is this just a tradition invented by Mário Filho surrounding soccer? In order to solve the issue, we used the precepts of discourse analysis and two widely circulated national journals were selected: the newspaper "O Estado de São Paulo" and "O Cruzeiro". Based on the materials investigated, we could see that he does not settle any kind of racial prejudice. Thus, it is possible to say that the discourse of Mario Filho, when addressing the "rise of racism," from the narrative of the defeat of 1950, appears as an invented tradition.

Keywords: Soccer: history. Prejudice. Press.

Racismo y la derrota que no se olvida: un análisis de los discursos de Mario Filho y la prensa sobre la final del Mundial de 1950

Resúmen: El objetivo de este estudio es comparar el discurso establecido por Mário Filho en la segunda edición de "O Negro no Futebol Brasileiro", 1964, y las noticias han informado los periódicos de la época en cuanto a los jugadores de negro culpó de la derrota de 1950 . Ellos eran realmente culpables de la prensa brasileña, o si estamos hablando de una "tradición inventada" por Mário Filho rodea el fútbol? Con el fin de resolver el problema, hemos utilizado los preceptos de análisis del discurso y fueron seleccionados a partir de dos revistas de amplia circulación nacional: el diario "O Estado de Sao Paulo" y la revista "O Cruzeiro". Con base en los materiales estudiados, podemos ver que él no se conforma con cualquier tipo de prejuicio racial. Por lo tanto, se puede decir que el discurso de Mario Filho, al abordar la llamada "aumento del racismo", de la narración de la derrota de 1950, aparece como una tradición inventada.

Palabras-clave: Fútbol. Historia. Prejuicio. Prensa.

Movimento, Porto Alegre, v. 16, n. 04, p. 191-208, outubro/dezembro de 2010. 


\section{REFERÊNCIAS}

ABRAHÃO, B. O. L.; SOARES, A. J. O que o brasileiro não esquece nem a tiro é o chamado frango de Barbosa: questões sobre o racismo no futebol brasileiro. Movimento, Porto Alegre, v. 15, n. 02, p. 13-31, abril/junho de 2009.

ANDRADE, A. M. R.; CARDOSO, J. L. R. Aconteceu, virou manchete. Revista Brasileira de História, São Paulo, v. 21, n. 41, p. 243-264, 2001.

ARAÚJO, F. O rádio, o futebol e a vida. São Paulo: SENAC, 2001.

BARBOSA, M. O Cruzeiro: uma revista síntese de uma época da história da imprensa brasileira. Ciberlegenda, n. 7, 2002. Disponível em: <http://www.uff.br/mestcii/ marial6.htm>. Acesso em: 12 jul. 2010.

CAPRARO, A. M. Identidades imaginadas: futebol e nação na crônica esportiva brasileira do século XX. 374 f. Tese (Doutorado) - Curso de História, Departamento de História, UFPR, Curitiba, 2007.

CARDOSO, L. Sob censura. Jornal o "Estado de São Paulo" completa 135 anos. Disponível em: <http://www.luiscardoso.com.br/2010/01/04/sob-censurajornal-o-estado-de-sao-paulo-completa-135-anos/>. Acesso em: 15 jul. 2010.

CASTRO, R. O anjo pornográfico. São Paulo: Companhia das Letras, 1992.

FIORIN, J. L. Linguagem e ideologia. São Paulo: Ática, 1988.

FOUCAULT, M. A ordem do discurso. São Paulo: Loyola, 1998.

GINZBURG, C. Mitos, emblemas sinais: morfologia e história. São Paulo: Companhia das Letras, 1990.

GINZBURG, C. Nenhuma ilha é uma ilha: quatro visões da literatura inglesa. São Paulo: Companhia das Letras, 2004.

GINZBURG, C. O queijo e os vermes: o cotidiano e as idéias de um moleiro perseguido pela Inquisição. São Paulo: Companhia das Letras, 2006.

HELAL, R.; GORDON JR, C. Sociologia, história e romance na construção da identidade nacional através do futebol. In: HELAL, R.; SOARES, A. J.; LOVISOLO, H.. A invenção do país do futebol: mídia, raça e idolatria. Rio de Janeiro: Mauad, 2001.

HELAL, R.; GORDON JR, C.; SOARES, A. J.; LOVISOLO, H. A invenção do país do futebol: mídia, raça e idolatria. Rio de janeiro: Mauad, 2001.

HOBSBAWM, E; RENGER, T. (org.). A invenção das tradições. Rio de Janeiro: Paz e Terra, 1997.

Movimento, Porto Alegre, v. 16, n. 04, p. 191-208, outubro/dezembro de 2010. 
NOGUEIRA, A.; SOARES, J.; MUYLAERT, R. A Copa que ninguém viu e a que não queremos lembrar. São Paulo: Companhia das Letras, 1994.

ORLANDI, E. P. Discurso e leitura. São Paulo: Cortez: Universidade Estadual de Campinas, 2000.

ORTIZ, R. Cultura brasileira e identidade nacional. 5.ed. São Paulo: Brasiliense, 1994.

ORTIZ, R.. A linguagem e seu funcionamento: as formas do discurso. São Paulo: Brasiliense, 1983.

PERDIGÃO, P. Anatomia de uma derrota: 16 de Julho de 1950 - Brasil X Uruguai. Porto Alegre: L\&PM, 2000.

SOARES, A. J. Futebol Brasileiro e Sociedade: a Interpretação Culturalista de Gilberto Freyre. In: Futbologías. fútbal, identidad y violencia en América Latina. Buenos Aires: Clacso, 2003.

SOARES, A. J. História e Invenção de Tradições no Campo do Futebol. Revista Estudos Históricos, Rio de Janeiro, v. 13, n. 23, p. 119 - 146, 1999.

SOARES, A. J. Identidade nacional e racismo no futebol brasileiro. In: PRONI, M.; LUCENA, R. (Org.). Esporte: história e sociedade. Campinas: Autores Associados, 2002. P. 165-190.

Fontes

RODRIGUES FILHO, M. O Negro no Futebol Brasileiro. 2. ed. Rio de Janeiro: Civilização Brasileira, 1964.

O CRUZEIRO. Rio de Janeiro, 1950.

O ESTADO DE SÃO PAULO. São Paulo, 1950.

Financiamento: REUNI

Recebido em: 26.08.2010

Aprovado em: 01.11.2010

Movimento, Porto Alegre, v. 16, n. 04, p. 191-208, outubro/dezembro de 2010. 